\title{
Product Traceability and Identification: An Examination of Its Effectiveness at the Coca-Cola Company of Ghana Limited, Kumasi, Ghana, West Africa
}

\author{
Charles Akomea Bonsu', Adwoa Benewaa Brefo-Manuh ${ }^{2}$, Godlove Kyeremateng ${ }^{3}$ \\ ${ }^{1}$ Kumasi Polytechnic, Department of Entrepreneurship and Finance, Kumasi, Ghana, West Africa \\ ${ }^{2}$ Kumasi Polytechnic, Department of Management Studies, Kumasi, Ghana, West Africa \\ ${ }^{3}$ Coca Cola PLC Kumasi, Department of Stores, Kumasi, Ghana, West Africa \\ Email address: \\ akomeabev@gmail.com (C. A. Bonsu),adwoabenewaa2@gmail.com (A. B. Brefo-Manuh), akyelove@yahoo.com (G. Kyeremateng)
}

\section{To cite this article:}

Charles Akomea Bonsu, Adwoa Benewaa Brefo-Manuh, Godlove Kyeremateng. Product Traceability and Identification: An Examination of Its Effectiveness at the Coca-Cola Company of Ghana Limited, Kumasi, Ghana, West Africa. Science Journal of Business and Management. Vol. 4, No. 2, 2016, pp. 51-60. doi: 10.11648/j.sjbm.20160402.15

Received: February 26, 2016; Accepted: March 25, 2016; Published: April 12, 2016

\begin{abstract}
This research sought to examine the effectiveness of product traceability and identification systems in organizations in Ghana using the Coca-Cola Company Limited, Kumasi Plant as case study. The study population included all employees of the Coca Cola Bottling Company as well as distributors for the company. The study was conducted with a quantitative method, executed through questionnaires and interview. The sample size for the study was sixty. The study utilized a quantitative research approach along with a descriptive research design. The quantitative data collected were subjected to statistical analyses using simple linear regression and correlation analysis. Findings indicated that that Coca Cola Company Limited has effective mechanisms in place to oversee the effective implementation of traceability and identification systems. The study also showed that the traceability and identification system by Coca Cola Bottling Company Limited was significantly effective in tracking products in supply chain. This implied that the coca cola traceability system contributes significantly to tracking products in supply chain.
\end{abstract}

Keywords: Product Traceability and Identification, Tracking and Tracing, Identification Lots, Supply Chain

\section{Introduction}

The emergence of globalization has increased the market size of various organizations to global proportions. Advancements in information technology and transport systems have enabled organizations to deliver products to consumers across the globe in relatively short time frames. Product identification and traceability enables organizations to identify and track a product or a component to its point of origin: which may be a particular set, production line or time frame, field or supplier. In effect, product identification and traceability enables organizations to come up with processes for maintaining records of all materials and parts from purchasing to finished goods where a unique number identifies a part, set or finished product.

Product traceability and identification has become a global concept used in all types of industries for varying and divergent reasons. In the auto-industry, the recall of defective parts and products is enhanced by product tracking systems (Margeirsson, 2008). The meat packaging industry has also been positively affected by the livestock identification and traceability systems, effectively allaying fears of the spread of livestock diseases and guaranteeing the health of consumers (Manos and Manikas, 2010). A company's ability to trace its products, from the stage of pre-production to finished goods ensures that the flow of materials and information can be tracked both within the company and through a supply chain.

In the food and beverages industry, product traceability and identification has become integral to operations as well. According to Wang and $\mathrm{Li}$ (2006), identification and traceability systems enable organizations to optimize scheduling and production planning in order to reduce waste 
and ensure efficient use of raw materials. Identification and traceability systems enables increased coordination in supply chain networks (Banterle and Stranieri, 2008; Engelseth, 2009), ensure that information relating to the beverage is secured in both the internal and external supply chains (Donnelly et al., 2012), and enables organizations to track defective components or products already sold or on the market. Canavari et al., (2010) posits that an effective company can use traceability and identification systems as part of its broader competitive strategy.

According to Ruiz-Garcia et al, (2010), many factors may compel an organization to implement traceability and identification processes: government legislation, food and safety, production optimization, product quality, brand sustainability, consumer welfare, supply chain communication, certification and competitive advantages. In Ghana, laws guiding the identification and traceability of products are nonexistent, forcing the European Union to caution the nation in regards to a possible export refusal (ghananewsagency.org/economics/).

Due to the nonexistence of a law guiding traceability and identification of products, most organizations in Ghana ignore the need for traceability and identification systems. The few companies who have such systems in place tend to employ manual record taking systems of traceability and identification, disregarding computerized system such as radio frequency identification devices and barcodes which are more effective.

\subsection{Statement of the Problem}

In the aftermath of the European horse-meat-labeled-asbeef crisis, the European Union Commission enacted a decree dubbed the general food law which required all exports within and into the European Union to be documented to enable the tracking of their history and location in order to easily identify the sources of dangerous food products and subsequently remove them from the market (European Commission, 2002). This decree, set in 2002, was to be adapted by all countries by the year 2007 .

Until 2013 when the Ghana Export Promotion Authority (GEPA) started measures to roll out a geographical mapping system of food and beverage companies to create a national data basis for product traceability and identification, Ghana as a nation had done significantly little to put into effect any product tracking system. Besides the fact that the lack of seriousness and initiative on the part of government and industry to put into effect a tracking system puts Ghanaian food exports at a risk of a European Union food export ban, it also put the Ghanaian population who patronize these products under significant health and safety risks.

Some organizations in the food and beverage industry have initiated measures to track products and components of products in the supply chain and the Coca-Cola Company Limited is one of such organizations. The implementation of the system though has not been easy, fraught with various challenges and systemic lapses. Considering the fact that the Coca-Cola Company Limited as a multinational corporation is battling challenges to install an effective tracking system, one can only imagine the effective of similar efforts of product tracking from other companies. The study therefore finds it imperative to examine the effectiveness of product traceability and identification systems in effect in the Ghanaian food and beverage industry by using the Coca-Cola Company Limited as case study.

\subsection{Research Objectives}

The main objective of this study is to examine the effectiveness of product traceability and identification systems in organizations in Ghana using the Coca-Cola Company Limited, Kumasi Plant as case study. To effectively address the main objective, the following specific objectives are formulated:

1. Identify the current traceability and identification system in use at the Coca-Cola Company Limited, Kumasi branch.

2. Examine the effectiveness of the current traceability and identification system in tracking products and components in the supply chain.

3. Examine the adequacy of current traceability and identification system in meeting the expectations of the international community.

\subsection{Research Questions}

In order to achieve the above objectives, the following research questions were formulated to guide the study.

1. Which traceability and identification system is currently in use at the Coca-Cola Company Limited, Kumasi branch?

2. What is the level of effectiveness of the current traceability and identification system in tracking products and components in the supply chain?

3. What is the level of adequacy of current traceability and identification system in meeting the expectations of the international community?

\section{Literature Review}

\subsection{The Concept of Identification and Traceability}

Researchers and organizations alike have tried to come to a consensus on a common definition for identification and traceability. A commonly accepted definition for these terms has yet to emerge. Different definitions for the activities of identifying and tracking of goods reflect the diverse set of roles that identification and traceability systems can play, from simple trace back to quality verification.

The Webster's Dictionary (2011) defines identification as the capacity to recognize as being, to classify by characteristics. This definition feeds into the general definition for traceability which is the ability to follow or study out in detail, or step by step, the history of a certain activity or a process. Similarly, the International Organization for Standardization' (1994) defined identification and traceability as the ability to identify a 
product, trace the history, application, or location of that which is under consideration. In conformity to the definitions above, the European Parliament (2002) see traceability as the ability to trace and follow a food, feed, food producing animal or ingredients, through all stages of production and distribution.

This study relates more to the definition propounded by Moe (1998): traceability is the ability to track a product batch and its history through the whole, or part, of a production chain from harvest through transport, storage, processing, distribution and sales or internally in one of the steps in the chain. This particular definition takes into consideration the concept relating to all products and types of supply chain (Regattieri et al., 2007).

It is worth highlighting a few key insights from the literature. The ISO 9000:2000 Quality Management standard takes a fairly general view of traceability as the ability to trace the history, application or location of a product or ingredient, including the processing history and the location of the product after delivery (Golan et al., 2004). The terms identification, traceability and verification are often used interchangeably, when in fact they are quite different. It may be relatively easy to identify livestock (tags), but is often more difficult to accomplish traceability, and even more difficult to verify identity, traceability and quality (Smith et al., 2005).

\subsection{Tracking and Tracing}

Several authors distinguish between tracking (following food and food ingredients forward to downstream buyers) and tracing (tracing food and food ingredients back to upstream suppliers) (Meuwiseen, 2004; Schwägele, 2005). Van Dorp (2002) points out that there is no uniform understanding of tracking and tracing. The definitions vary from the dimensions of the type of activities that are included and the organizational context in which they are performed. Stefansson and Tilanus (2000) indicate that tracking usually stands for following the entity on its way from A to B, while tracing stands for finding the entity between $\mathrm{A}$ and $\mathrm{B}$. Schwägele (2005) defines tracking as the ability to follow the path of an item as it moves downstream through the supply chain from the beginning to the end, and tracing as the ability to identify the origin of an item or group of items, through records, upstream in the supply chain.

Although the quality of the transportation process could be very high, a tracking and tracing system could still bring benefits from other aspects. According to Stefansson and Tilanus (2000), it could be applied for administrative purpose, for example, serving as a basis for payments to haulers. Furthermore, the collected data could be statistically processed and established into an information system to confirm if the quality of the process is maintained at a satisfied level. Traceability also covers everything related to the products before, during and after the manufacturing, packaging, and distribution process, which involves ingredients, processes, test and test results, environment, resources used, transport methods etc. (Schwägele, 2005).

Based on van Dorp's (2002) finding, by considering the quality variation on tactical and operational production levels, two types of tracking and tracing definitions could be established, tracking and tracing in a restricted sense and tracking and tracing in an extensive sense (van Dorp, 2002). Golan et al. $(2003$; 2004) asserts that the main difference between tracing in a restricted sense and tracking and tracing in an extensive sense is that the later one encompasses the former one and enables the traceability information to be used in multi-dimensional areas in the supply chain instead of only focusing on tracing products.

\subsubsection{Necessity of Traceability}

According to European Commission (2007), traceability is a cornerstone of the EU's food safety policy. Traceability is a risk-management tool which offers the possibility to response to potential risks that can arise in food and feed, and provide the chance for food business operators or authorities to isolate the problem by withdrawing or recalling and then prevent contaminated or unsafe products from reaching consumers.

Many researchers pointed out that efficient traceability in food supply chains has the potential to reduce risks and costs associated with food borne diseases and eliminate food safety hazards. For example, traceability reduces medical costs (Hobbs et al., 2005), reduces labor productivity losses (Kelepouris et al., 2007; Lee and Özer, 2007; Chryssochoidis et al., 2009; Veronneau and Roy, 2009; Mehrjerdi, 2010), reduces recall scope and time (Hobbs et al., 2005; Banterle and Stranieri, 2008; Bechini et al., 2008; Bevilacqua et al., 2009), and ensures the consistent safety of food (Pettitt, 2001; Meuwissen et al., 2003; Beulens et al., 2005; Schwägele, 2005).

Another function of traceability is that it provides targeted and accurate information concerning a certain product to the customers and enables the customers to acquire the relevant information related to the food safety and quality issue, thus, customers are willing to pay a higher price for products under certain guaranteed circumstances or coming from a desired origin (Hobbs et al., 2005; Loureiro and Umberger, 2007; Summer and Pouliot, 2008; Chryssochoidis et al., 2009). Consequently, companies that can provide such effective traceability systems for their products not only increase safety precautions in operations but also enhance customers confidence and trust through the assurance of quality and safety (Shanahan et al., 2009, Mai et al., 2010). Effective traceability systems can also add more value of the products then enhance the total profits. This can be viewed as a mutual benefits situation (Chryssochoidis et al., 2009).

Proper traceability systems also have a potential to decrease the probability of a supplier or an operator with responsibility for a product safety problem by providing well-documented traceable data to prove that they comply with regulatory requirements and do not present risks (Meuwissen et al., 2003; Sahin et al., 2007; Fritz and Schiefer, 2009). In that condition, liability claims and lawsuits will be avoided and company image will not be affected (Mai et al., 2010). 


\subsubsection{Functions of Traceability}

According to Hobbs (2004) Traceability has three main functions to be performed, which are the follows: First, is to make the trace back of the products easy and rapid in the event of a contaminated product or one, which does meet product standards, if it has to be removed from the market. By this, an effective traceability program limits the problem from spreading more and reduces the cost for companies of the impact of a recall or market withdrawal (e.g. less reduced loss of sales, less lost revenue, less affected product on the market, less damage to the company image and less lost goodwill with customers and the general public).

Accurate and complete tracking records for products can reduce the impact of a product recall by limiting the scope since potentially affected product can be better defined and contained. If there is an illness outbreak associated with food, traceability programs can provide background information that could improve diagnoses and reduce the overall cost for patient care since it may be possible to determine more quickly and accurately which individuals may have been made ill by an implicated food.

Second, is the ability to mitigate damages in a contract, commercial law and tort actions. The primary losses from a food recall to an affected firm come from disruptions in the supply chain. Consumer litigation under state product liability and consumer protection laws exposes a company responsible for the distribution of allegedly contaminated food to strict liability. The company distributing a contaminated product is likely liable for any damages resulting from the consumption of the food regardless of whether or not the company was negligent.

Buzby and Frenzen (1999; Buzby et al., 2001) point out that the legal incentives for firms to produce safer foods and practice due diligence in the developing countries are limited, because less than the $0.01 \%$ of the cases of food borne illness are taken to court, most likely because the source of contamination could not be attributable to a particular food product, and in addition, because negligent consumer food handling practices could not be ruled out. In the cases that are litigated, the rate of compensation is low. Regardless, the application of traceability provides an incentive to avoid litigation, particularly as it becomes widely adopted throughout the industry.

A common legal standard for a defendant in suits brought under a negligence cause of action is that of a prudent processor an individual or company that can be shown to have exercised reasonable care in processing and handling a food. As industry practices improve, the level of care required of processors increases causing both a market driven improvement in food safety and an improvement in overall quality standard practices. It is possible that litigation will find fault with the effectiveness of a company's traceability program and introduce this deficiency in a food traceability program as evidence that the company failed to exercise reasonable care.

For food products, including food and drugs board regulated products, where traceability is mandated by regulation, failing to have a traceability program will constitute negligence per se, providing some evidence, but not conclusive evidence, that a company was negligent (Rasco, 1997; Buzby et al., 2002). Regardless of the legal theory that might be employed to impose liability upon a company, traceability programs will provide another incentive for firms to produce safer food, because they will know that in the case of an outbreak the supplier of the infected product could be easily determined.

Third, is basis for a developing a traceability program is for pre-purchase quality verification. With traceability information, a purchaser will be able to have relevant information on the quality properties of a product. With traceability, a purchaser may also be able to verify growing conditions, inspection protocols and nutrient content in addition to the information that is already provided such as the packing date, place, and producer etc. and what can be recovered through barcodes or product labeling to identify product features.

\subsubsection{Different Types of Traceability Models}

According to Hobbs (2004a), there are two distinct models for traceability: ex post traceability and an ex ante quality verification systems. An ex post traceability system would be appropriate in the case of a food borne disease outbreak or intentional contamination incident. It traces back the product to the lot or source of contamination and then traces forward to locate the contaminated product in the marketplace, providing the ability to isolate it from unaffected products.

Theoretically, similar products, which were not affected, would not be involved in the market withdrawal, reducing the costs of a recall and, hopefully, saving a company's reputation. As Hobbs (2004a) points out, there are three additional costs for a company in the case of an outbreak that results in a market withdrawal. The first cost is the market penalty cost if the company is the provider of the contaminated food. A market penalty cost for a specific firm, is the cost associated with the loss of demand for the products, because fewer consumers are willing to purchase their products, which in turn, leads to lower revenue.

The second cost is the legal liability cost imposed on a firm, which is the supplier of the contaminated products since food producers, in parts of the world like the United States and the EU are strictly liable for damages such food borne illness or physical injury if a consumer is injured by consumption of their product. This cost greatly exceeds Hobb's concept of due diligence in producing food as companies are liable for damages without fault. Employment of industry best practices will not insulate a company from strict liability claims. Due diligence is some protection against cases arising under a negligence cause of action and involves the steps taken to produce safer foods or products.

The third cost discussed by Hobbs (2004a) arises is named externality cost. Because contaminated product suppliers cannot be detected in the absence of traceability system, all the firms operating in the industry incur the cost caused by a lower demand by consumers for all the industry products 
regardless of the provider of the product because of a lack of confidence in the product category. This is known as an externality cost. Ex ante quality verification works differently than ex post programs. In an ex ante system, a third party verifies the quality of the products or the compliance of the producers with the standards. The effectiveness of such a program from a profit maximizing company depends on the effectiveness of the monitoring party.

As Hobbs (2004) claims traceability has little value for physical quality characteristics identifiable by the buyer through a search process prior to purchase (Hobbs, 2004a). An ex ante program can verify following attributes such as:

\section{Methodology}

\subsection{Research Design}

The study adopted a mixed (quantitative and qualitative) research approach using a descriptive research design. Burns and Grove (1993) have defined quantitative research approach as a methodical/ procedural approach, guided by strict and testable objectives. Qualitative research on the other hand has been described as an approach used to gain understanding of the settings and underlying conditions by analysis existing secondary data related to the research topic (Amin, 2005. The study adopted a case study approach focusing on the Coca Cola Bottling Company of Ghana

\subsection{Population of the Study}

The study population included all employees of the Coca Cola Bottling Company as well as distributors for the company. The total number of employees of the coca cola company (Kumasi Plant) was two hundred and twenty four (224).

\subsection{Sample and Sampling Technique}

A sample size of sixty (60) respondents was purposively selected from the total study population, made up of forty (40) employees of The Coca Cola Bottling Company and twenty (20) distributors. Both employees of The Coca Cola Bottling Company and its distributing companies were purposively selected based on perceived knowledge on the research topic, rank within the company, experience and level of education. Purposive sampling was done to enable the study target respondents in critical positions within The Coca Cola Bottling Company and selected distributing companies who could provide authentic and adequate data for the study. The sample size was considered adequate by the researcher because it was in line with the assertion of Britton and Garmo (2002) who state that a sample size, when purposively selected to be representative of the study population, can be effectively generalized.

\subsection{Primary Data}

According to Yin (2005), primary data sources consist of questionnaires and interviews (structure or unstructured), observations, group discussions, etc. Primary data sources used in the study consisted of first-hand data collected from the sampled respondents. These data sources included questionnaires and semi-structured interviews.

\subsection{Questionnaire}

Questionnaires were used by the study to collect primary data. According to Yin (2005), a questionnaire is set of structured questions printed on a paper and given to a study respondent to answer. Britton and Garmo (2002) posits that a questionnaire has great advantages over other data collection instruments in that, it allows the respondents freedom to be objective in their responses although they tend to have less depth.

The questionnaires were administered by the researcher personally at the offices of the respondents. Having obtained permission to go ahead from the various heads of the various units of the coca cola bottling company, the researcher approached the respondents and sought their agreement to participate in the study. The selected distributors were also reached in their places of work and persuaded to provide data for the study.

The questionnaire was concise and close-ended, to allow for quick guided responses so as to enable categorization of response groups. A 5-point Likert scale was used in measuring responses obtained. The questionnaire included 2 sections. Section 1 solicited demographic data of the study respondents to confirm the purposive sampling criteria as determined by the study.

\subsection{Data Analysis Procedure}

Data collected from the primary data collection instruments were sorted and coded manually into the Statistical Package for Social Sciences (SPSS) computer software. Statistical analysis such as factor analysis and inferential analysis (correlation and regression) were used to analyze data. The findings were presented in tables and columns.

To measure the variable and spread of data set and the relationships of the mean to the rest of the data, the study conducted standard deviation analysis. The closeness of the data points to the mean indicated the uniformity or other of the responses. When data points are close to the mean, the responses are fairly uniform, when data points are not close to the mean, the responses have a wide variance, then the standard deviation will be large. If all the data values are equal, then the standard deviation will be zero.

The standard deviation was calculated using the following formula.

$\mathrm{S} 2=\Sigma(\mathrm{X}-\mathrm{M})^{2} / \mathrm{n}-1$

Where $\Sigma=$ Sum of

$\mathrm{X}=$ Individual score

$\mathrm{M}=$ Mean of all scores

$\mathrm{N}=$ Sample size (number of scores)

To give the mean and standard deviation analysis further meaning, the study calculated the relationship of the standard deviation to the mean, also known as coefficient of variation 
(CV). The coefficient of variation analysis allowed the study to have a more uniform method of determining the relevance of the standard deviation and what it indicates about the responses of the sample. The closer the $\mathrm{CV}$ is to 0 , the greater the uniformity of data. The closer the CV is to 1 , the greater the variability of the data. The equation used in calculating the coefficient of variation was also indicated below.

$$
\mathrm{CV}=\mathrm{S} / \mathrm{M}
$$

\subsection{Multiple Regression Models}

In examining examine the effectiveness of product traceability and identification systems in the Coca-Cola Company Limited (Kumasi Plant), the study utilized multiple regression models as follows;

$$
\mathrm{Y}_{\mathrm{it}}=\mathrm{f}
$$

Where,

Equation 1 is functional equation

$\mathrm{Y}_{\mathrm{it}}=$ dependent variable

$\alpha=$ the intercept: it remains constant when all the independent variable are equal to zero $(0)$

$\beta=$ coefficient of independent variables: it explains the rate of change in the independent variables.

$\varepsilon_{\text {it }}=$ error term: it represents other explanatory variables that are not included in the model. $\alpha$ is a constant $\beta 1 \ldots . . \beta 6$ are the coefficients of their representative variables while $i$ an $t$ are firm specific and time respectively. $\varepsilon_{\text {it }}$ is the error term

\section{Data Presentation, Analysis and Discussion of Findings}

\subsection{Requirements Set out by the International Community Regarding Product Traceability and Identification}

Research objective one sought to examine the requirements set out by the international community regarding product traceability and identification. The study sought for the respondents to identify the requirements as they knew it and as had been presented on the questionnaire. Out of the 60 respondents sampled, made up of 40 employees of the Coca Cola Bottling Company Limited and the 20 suppliers and distributor, the study found that $97 \%$ of respondents identified the requirement for company to give unique identification to their product before distribution. $95 \%$ of respondents identified data capture and recording, 92\% identified data communication throughout the supply chain whilst $78 \%$ identified the requirement for companies to ensure that links between the various supply chain points are effectively managed.

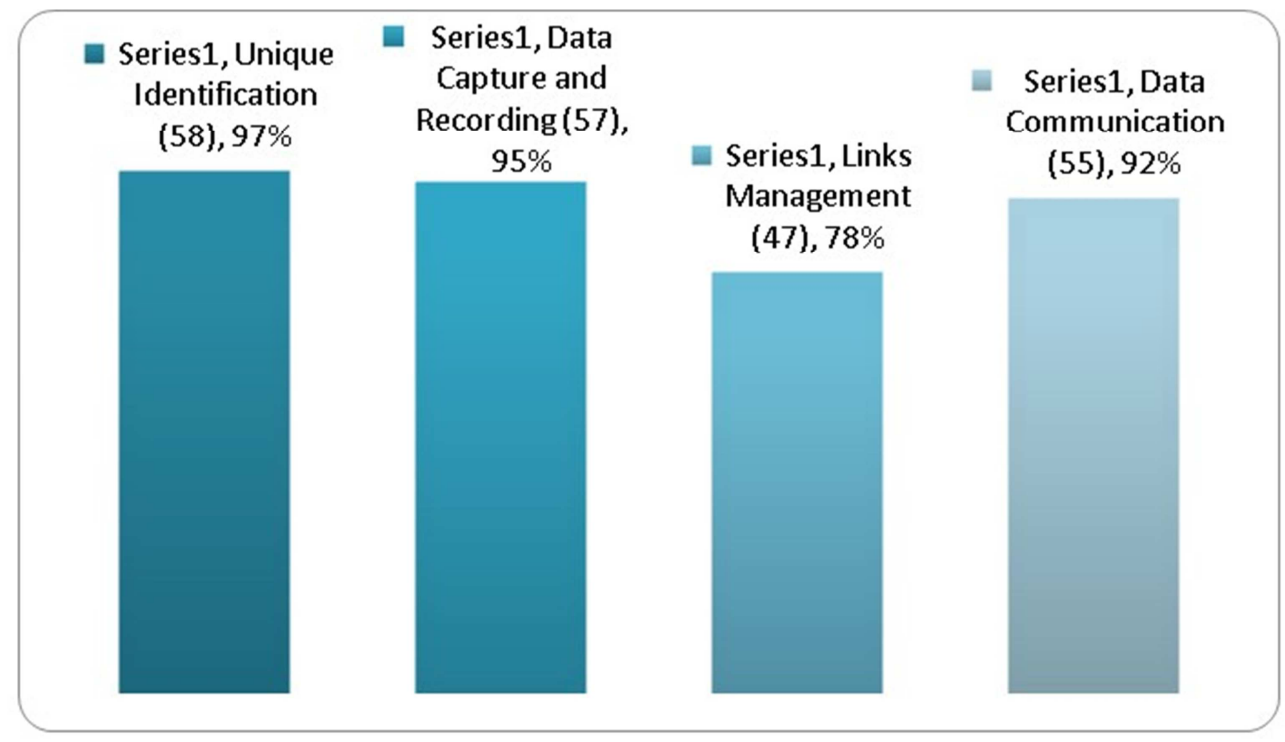

Source: Field Data, August, 2015

Figure 1. Categories of Traceability and Identification Requirements.

The findings of this study correlated to findings made in other studies and to current literature on the topic. Golan et al., (2004) sampled 354 companies under the European Union traceability and food safety initiative and found that as general requirements, companies involved in the European Union food market observe four general principles in effectively observing traceability and identification policies: unique identification, data capture and recording, links management and data communication. This finding is also supported by Smith et al., (2005) who state that international regulatory require unique identification of locations and should be ensured through the allocation of an EAN, UCC Global Location Number (GLN), to each location and functional entity.

Having identified the categories of requirement imposed by the international community on food and beverages 
companies like the Coca Cola Bottling Company Limited, the study sought to find out if there were any degrees of association between the categories of traceability and identification requirements. To achieve this, a Pearson correlation analysis with a confidence interval of $95 \%$ using a 2-tailed test of significance was performed to test the relationship between the identified categories of traceability and identification. The variables used in the correlation analysis included the four (4) major categories: unique identification, data capture and recording, links management and data communication.

Table 1. Correlation Analyses of Categories of Traceability and Identification Requirements.

\begin{tabular}{lllll}
\hline & Unique Identification & Data Capture and Recording & Links Management & Data Communication \\
\hline Unique Identification & 1 & $.809^{* *}$ & $.353^{* *}$ & $.616^{* *}$ \\
Data Capture and Recording & $.809^{* *}$ & 1 & $.436^{* *}$ & $.761^{* *}$ \\
Links Management & $.353^{* *}$ & $.436^{* *}$ & 1 & $.573^{* *}$ \\
Data Communication & $.616^{* *}$ & $.761^{* *}$ & $.573^{* *}$ & 1 \\
\hline
\end{tabular}

Source: Field Data, August, 2015

From table 1, it can be inferred that significant correlations was found between all the four Categories of Traceability and Identification Requirements. Unique identification was found to positively correlate to data capture and recording $\left(.809^{* *}\right.$, Sig. 0.00), to links management $\left(.353^{* *}\right.$, Sig. 0.00$)$ and data communication $\left(.616^{* *}\right.$, Sig. 0.00) in a similar vein, data capture and recording correlate significantly with links management $\left(.436^{* *}\right.$, Sig. 0.00$)$ and data communication $\left(.761^{* *}\right.$, Sig. 0.00). Lastly, links management also correlate with data communication $\left(.573^{* *}\right.$, Sig. 0.00$)$. The findings showed that the traceability and identification requirement as set out by the international regulatory bodies are correlated one to another, in a sense that ineffective performance of one would certainly affect the effective performance of another.

Table 2. Unique Identification System at Coca Cola Ghana.

\begin{tabular}{lllll}
\hline & N & Mean & Std. Deviation & C.V \\
\hline $\begin{array}{l}\text { Identification of } \\
\text { locations of products }\end{array}$ & 60 & 2.2167 & 1.30308 & 0.5878 \\
$\begin{array}{l}\text { Identification of trade } \\
\text { items }\end{array}$ & 60 & 4.0667 & .91812 & 0.2257 \\
$\begin{array}{l}\text { Identification of series } \\
\begin{array}{l}\text { Identification of } \\
\text { lots/batches }\end{array}\end{array}$ & 60 & 2.4333 & 1.47713 & 0.6070 \\
$\begin{array}{l}\text { Identification across } \\
\text { product hierarchies }\end{array}$ & 60 & 4.3167 & 1.29525 & 0.3905 \\
$\begin{array}{l}\text { Identification of } \\
\text { logistic units (pallets) }\end{array}$ & 60 & 4.1000 & 1.17459 & 0.2864 \\
\hline
\end{tabular}

Source: Field Data, August 2015

The study showed that the Coca Cola Bottling Company Limited engages in some practices under the Unique Identification requirement but does not adhere to other practices. The study showed that the company as fulfillment of the unique identification requirement, practices mechanisms to identify logistics units (pallets) (mean=4.1000, $\mathrm{CV}=0.2864$ ), identify product hierarchies (mean=4.0333, $\quad \mathrm{CV}=0.2775$ ), identify trade items (mean=4.0667, $\mathrm{CV}=0.2257$ ) and identify lots / batches (mean=3.3167, $\mathrm{CV}=0.3905$ ). The study showed that although the company has mechanisms in place to ensure some forms of unique identification, other measures of unique identification were found not adhered to by the company: unique identification of locations of products and unique identification of series. This showed that the company at any point in their supply chain system did not know the location of their products, especially along the distribution lines outside of the company.

Table 3. Traceability Links Management

\begin{tabular}{|c|c|c|c|c|}
\hline & $\mathbf{N}$ & Mean & Std. Deviation & C.V \\
\hline $\begin{array}{l}\text { Links management by } \\
\text { production batch }\end{array}$ & 60 & 3.8500 & 1.07080 & .13824 \\
\hline $\begin{array}{l}\text { Supplier of Uniform logistic } \\
\text { units and cross docking }\end{array}$ & 60 & 2.1000 & 1.10008 & .14202 \\
\hline $\begin{array}{l}\text { Materials are stored and/or } \\
\text { ordered for the production } \\
\text { process. consumer units (GTIN } \\
\text { 1) are produced in separate } \\
\text { batches }\end{array}$ & 60 & 4.6000 & .86749 & .11199 \\
\hline $\begin{array}{l}\text { Consumer units (GTIN 1) are } \\
\text { produced in separate batches }\end{array}$ & 60 & 4.2667 & 1.20545 & .15562 \\
\hline $\begin{array}{l}\text { Recording links between } \\
\text { newly created logistic units } \\
\text { and their components }\end{array}$ & 60 & 4.2833 & 1.13633 & .14670 \\
\hline $\begin{array}{l}\text { In the packaging step, } \\
\text { consumer units are packed into } \\
\text { standard grouping units }\end{array}$ & 60 & 2.0167 & 1.11221 & .14359 \\
\hline
\end{tabular}

Source: Field Data, August 2015

The study showed that in relation to traceability links management, Coca Cola Bottling Company practices recording links between newly created logistic units and their components (mean=4.2833, $\mathrm{CV}=.14670)$, consumer units (GTIN 1) are produced in separate batches (mean $=4.2667$, $\mathrm{CV}=.15562$ ), Materials are stored and/or ordered for the production process, consumer units (GTIN 1) are produced in separate batches (mean=4.6000, $\mathrm{CV}=.11199)$ and Links management by production batch (mean $=3.8500, \mathrm{CV}=.13824$ ). The study showed that Coca Cola has mechanisms in place to ensure effective traceability links management.

\subsection{Effectiveness of the Current Traceability and Identification System in Tracking Products and Components in the Supply Chain}

Research objective three sought to examine the effectiveness of current traceability and identification systems in tracking and components in the supply chain at the Coca Cola Bottling Company. To achieve this, the study 
tested the effectiveness of the traceability system at Coca Cola Company Limited in tracking product tracking. In this analysis, Coca Cola Traceability System was treated as independent variable whilst Tracking Products in Supply Chain was treated as dependent variable. The results are presented in table 4 below. The equation of a simple linear regression is: $\mathrm{Y}=\mathrm{a}+\mathrm{b} 1 \mathrm{x} 1$, where $\mathrm{Y}$ is the value of the dependent variable (what is being predicted), $\mathrm{a}=$ constant and $\mathrm{b} 1=$ slope (beta coefficient) for $\mathrm{x} 1$, where $\mathrm{x} 1$ is the independent variable (Coca Cola Traceability System).

Table 4. Forced Entry Regression of Traceability on Product Tracking.

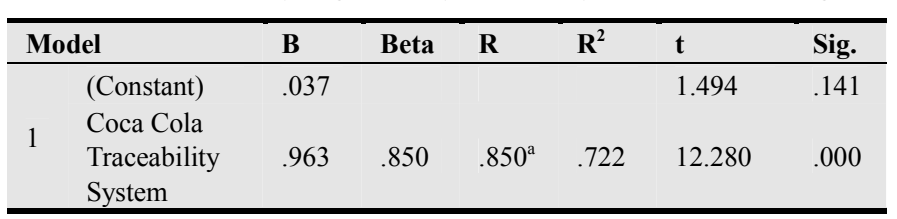

a. Dependent Variable: Tracking Products in Supply Chain

Source: Field Data, 2015

In table 4 it can be inferred that the coca cola traceability system has significant effectiveness in tracking products in supply chain (beta $=.850, \mathrm{t}=12.280, \mathrm{p}<.000$ ). This implies that the coca cola traceability system contributes significantly to tracking products in supply chain. The model also predicted that for every unit increase in the traceability system at Coca Cola, efficiency of tracking products in supply chain improves by 963 units. Also, the contribution of the traceability system at Coca Cola to track products in supply chain accounted for $7.22 \%$ (i.e., $\mathrm{R}^{2}=.722$ ). Therefore the efficiency of the traceability system that was explained by the independent variable (traceability system) was $7.22 \%$. The $722 \%$ shared variance was maximum effect size between the variables in the study since the model was able to explain the variation in the model (Cohen, 1988). Thus, the study objective was realized as there was a statistically significant effect of the Coca Cola traceability system in ensuring efficiency in the tracking of products in the supply chain.

\section{Summary of Findings}

The purpose of the study was to examine the effectiveness of product traceability and identification systems in organizations in Ghana using the Coca-Cola Company Limited, Kumasi Plant as case study. The findings of the study can be summarized as follows:

Research objective one sought to identify the current traceability and identification system in use at the Coca-Cola Company Limited, Kumasi branch. The study showed that Coca Cola Company Limited has effective mechanisms in place to oversee the conduct of practices traceability and identification systems.

Research objective three sought to examine the effectiveness of the current traceability and identification system in tracking products and components in the supply chain. It could be inferred that the coca cola traceability system has significant effectiveness in tracking products in supply chain. This implies that the coca cola traceability system contributes significantly to tracking products in supply chain. The model also predicted that for every unit increase in the traceability system at Coca Cola, efficiency of tracking products in supply chain improves by 963 units.

Research objective four sought to examine the adequacy of current traceability and identification system in meeting the expectations of the international community. The study showed a majority of respondents see the adequacy of Coca Cola traceability and identification system as either high or very high in meeting the requirements and expectations of the international community.

\section{Conclusion}

Traceability and identification systems are a proven way to ensure that goods in the supply chain system are effectively monitored and tracked to enable unwholesome goods and products to be taken away from the supply chain in the event of the realization of unhealthy occurrences. This system has served to curb meat disease pandemics in European countries and if effectively adopted in developing countries like Ghana, could serve as a surety of confidence for the Ghanaian food and beverages industry. The study showed that the Coca Cola company limited has made strides in installing practices and observing requirement towards effective product traceability and identification. However, the study also found deficiencies in the system and has therefore made recommendations that the researcher believes would effectively strengthen the company's product traceability and identification system.

\section{Recommendations}

Based on the findings, the study recommends the following:

Create Office to Oversee Traceability and Identification Processes

The study showed that the traceability and identification system is a process that is performed by various sections and departments in the organization. Due to this, the oversight of the process has in time become the responsibility of no one department or section, thereby rendering the system prone to errors and fluctuations in levels of quality. The study therefore recommends that the Coca Cola Company Limited creates an office that would be responsible to the overall oversight of the traceability and identification process.

Ensure the Performance of All Necessary Processes

The study showed that under unique product identification and other categories of requirements, the Coca Cola Company Limited showed a deficiency. The study showed that the company performed some practices, especially under the unique identification requirement but failed to perform other necessary practices to complement the unique identification process. The study therefore recommends that Coca Cola Bottling Company Limited takes measures to ensure that all necessary practices are performed under each of the stated categories of product traceability and identification. 


\section{References}

[1] Abad, E, Palacio, F, Nuin, M, Zárate, AGD, Juarros, A, Gómez, JM and Marco, S (2009), "RFID smart tag for traceability and cold chain monitoring of foods: Demonstration in an intercontinental fresh fish logistic chain", Journal of Food Engineering, Vol 93, pp. 394-399.

[2] Banterle, A., \& Stranieri, S. (2008). The consequences of voluntary traceability system for supply chain relationships. An application of transaction cost economics. Food Policy, 33(6), 560e 569.

[3] Bechini, A, Cimino, MGCA, Marcelloni, F and Tomasi, A (2008), "Patterns and technologies for enabling supply chain traceability through collaborative e-business", Information and Software Technology, Vol 50, pp. 342-359.

[4] Beulens, AJM, Broens, D-F, Folstar, P and Hofstede, GJ (2005), "Food safety and transparency in food chains and networks Relationships and challenges", Food Control, Vol 16, pp. 481-486.

[5] Bevilacqua, M, Ciarapica, FE and Giacchetta, G (2009), "Business process reengineering of a supply chain and a traceability system: A case study", Journal of Food Engineering, Vol 93, p. 13-22.

[6] Buckley, DJ (1997), The GIS premier: An Introduction to Geographic Information Systems, viewed 24 May 2011, $<$ http://bgis.sanbi.org $>$.

[7] Buzby, J., P. Frenzen and B. A. Rasco. (2001). "Product Liability and Food Safety: The Resolution of Food Poisoning Laws." In: Interdisciplinary Food Safety Research. N. Hooker and E. A. Murano (eds). CRC Press. Boca Raton, FL. p. 121-137.

[8] Buzby, J. C., and P. Frenzen. (1999). "Food Safety and Product Liability." Food Policy, 24: 637-651.

[9] Buzby, J. C., P. Frenzen and B. A. Rasco. (2002). "Jury Decisions and Awards in Personal Injury Lawsuits Involving Food Borne Pathogens. J. Consumer Affairs, 36(2):220-238.

[10] Buzby, J. C., P. D. Frenzen and B. A. Rasco. (2001). "Product Liability and Microbial Foodborne Illness." United States Department of Agriculture, Agricultural Economic Report No. 799. U.S.D.A., Beltsville, MD. p.41.

[11] Canavari, M., Centonze, R., Hingley, M., \& Spadoni, R. (2010). Traceability as part of competitive strategy in the fruit supply chain. British Food Journal, 112(2), 171e184.

[12] Dana, PH (2000), Global Positioning System Overview, viewed $24 \quad$ May 2011, $<$ http://www.colorado.edu/geography/gcraft/notes/gps/gps_f.h tml>.

[13] Deng, X, Lu, X, Zheng, S, Ma, W, Ren, Z and Chen, X (2008), "GIS-based traceability system of agricultural product safety", Transactions of the Chinese Society of Agricultural Engineering, Vol 24, pp. 172-176.

[14] Donnelly, K. A.-M., Karlsen, K. M., \& Dreyer, B. (2012). A simulated recall study in five major food sectors. British Food Journal, 114(7), 1016e1031.

[15] Engelseth, P. (2009). Food product traceability and supply network integration. Journal of Business \& Industrial Marketing, 24(5/6), 421e430.
[16] Fritz, M and Schiefer, G (2009), "Tracking, tracing, and business process interests in food commodities: A multi-level decision complexity", Int. J. Production Economics, Vol 117, pp. 317-329.

[17] Galvao, JA, Margeirsson, S, Garate, C, Viðarsson, JR and Oetterer, M (2010), "Traceability system in cod fish", Food Control, Vol 21, p. 1360-1366.

[18] Ghribi, M, Hubina, T, Longo, G, Lounissi, R and Sayahi, L (2010), International Centre for Science and High Technology of the United Nations Industrial Development Organization, viewed 10 June 2011, <http://www.ics.trieste.it/homepage.aspx $>$.

[19] Golan, E, B. Krissoff, F. Kuchler, 1. Calvin, K. Nelson, and G. Price. (2004). "Traceability in the U.S. Food Supply: Economic Theory and Industry Studies." Retrieved aJanuary 25, 2006 from http://www.ers.usda.gov/publications/aer830

[20] GS1 (2007), 'The GS1 Traceability Standard: What you need to know', GS1, GS1, Brussels.

[21] GS1 (2011), Overview of GS1, viewed 22 June 2011, $<$ http://www.gs1.org/about/overview>.

[22] Hall, D (2010), "Food with a visible face: Traceability and the public promotion of private governance in the Japanese food system", Geoforum, Vol 41, pp. 826-835.

[23] Hart, D (2007), Introduction to Global Positioning Systems GPS, viewed 24 May 2011, $<$ http://aqua. wisc.edu/cpr/Default.aspx?tabid=80>.

[24] Hobbs, JE, Bailey, D, Dickinson, DL and Haghiri, M (2005), "Traceability in the Canadian Red Meat Sector: Do Consumers Care?" Canadian Journal of Agricultural Economics, Vol 53, pp. 47-65.

[25] International Organization for Standardization (1994), ISO standard 8402:1994, viewed 28 May 2011, $<$ http://www.iso.org $>$.

[26] Kelepouris, T, Pramatari, K and Doukidis, G (2007), "RFIDenabled traceability in the food supply chain", Industrial Management \& Data Systems, Vol 107, No. 2, pp. 183-200.

[27] Lai, F, Hutchinson, J and Zhang, G (2005), "Radio frequency identification (RFID) in China: opportunities and challenges", International Journal of Retail \& Distribution Management, Vol 33, No. 12, pp. 905-916.

[28] Lee, H and Özer, Ö (2007), "Unlocking the Value of RFID", Production and Operations Management, Vol 16, No. 1, pp. 40-64.

[29] Li, S, Visich, JK, Khumawala, BM and Zhang, C (2006), "Radio frequency identification technology: applications, technical challenges and strategies", Sensor Review, Vol 26, No. 3, p. 193-202.

[30] Loureiro, ML and Umberger, WJ (2007), "A choice experiment model for beef: What US consumer responses tell us about relative preferences for food safety, country-of-origin labeling and traceability", Food Policy, Vol 32, pp. 496-514.

[31] Mai, N, Bogason, SG, Arason, S, Arnason, SV and Thorolfur Geir, M (2010), "Benefits of traceability in fish supply chains - case studies", British Food Journal, Vol 112, No. 9, pp. 9761002 . 
[32] Manos, B., \& Manikas, I. (2010). Traceability in the Greek fresh produce sector: drivers and constraints. British Food Journal, 112(6), 640e652.

[33] Margeirsson, S. (2008). Processing forecast of cod e Decision making in the cod industry based on recording and analysis of value chain data. Reykjavik, Iceland: Faculty of Engineering, University of Iceland.

[34] Qu, X, Zhuang, D and Qiu, D (2008), "Construction and Application of GIS Based Green stuff Traceability Logistics System", GeoO-Information Science, Vol 10, No. 5, pp. 615622.

[35] Rasco, B. A. (1997). "Products liability and HACCP." Food Quality. Oct. p.16-18.

[36] Rasco. B. A. and G. E. Bledsoe. (2005). Bioterrorism and Food Safety. CRC Press. Boca Raton, FL. p. 414.

[37] Regattieri, A, Gamberi, M and Manzini, R (2007), "Traceability of food products: General framework and experimental evidence", Journal of Food Engineering, Vol 81, pp. 347-356.

[38] Rizos, C (1999), Satellite Navigation \& Positioning Laboratory, viewed 24 May 2011, $<$ http://www.gmat.unsw.edu.au/snap/gps/gps_notes1.pdf $>$.

[39] Ruiz-Garcia, L., Steinberger, G., \& Rothmund, M. (2010). A model and prototype implementation for tracking and tracing agricultural batch products along the food chain. Food Control, 21(2), 112e121.

[40] Shanahan, C, Kernan, B, Ayalew, G, McDonnell, K, Butler, F and Ward, S (2009), "A framework for beef traceability from farm to slaughter using global standards: An Irish perspective", Computers and Electronics in Agriculture, Vol 66, p. 62-69.

[41] Shrivastava, P (1995), "Ecocentric Management for a Risk Society", Academy of Management Review, Vol 20, No. 1, pp. 118-137.
[42] Smith, GC, Tatum, JD, Belk, KE, Scanga, JA, Grandin, T and Sofos, JN (2005), "Traceability from a US perspective", Meat Science, Vol 71, p. 174-193.

[43] Stefansson, G and Tilanus, B (2000), "Tracking and tracing: principles and practice", International Journal of Technology Management, Vol 20, No. 3, pp. 252-271.

[44] Summer, DA and Pouliot, S (2008), "Traceability, Liability and Incentives for Food Safety and Quality", American Journal of Agricultural Economics, Vol 90, No. 1, p. 15-27.

[45] Van Dorp, K-J (2002), "Tracking and tracing: a structure for development and contemporary practices", Logistics Information Management, Vol 15, No. 1, pp. 24-33.

[46] Veronneau, S and Roy, J (2009), "RFID benefits, costs, and possibilities: The economical analysis of RFID deployment in a cruise corporation global service supply chain", International Journal of Production Economics, Vol 122, pp. 692-702.

[47] Wang, X., \& Li, D. (2006). Value added on food traceability: a supply chain management approach. In IEEE conference on service operations and logistics, and informatics (SOLI 2006) (pp. 493e498). Shanghai, China: The Institute of Electrical and Electronics Engineers (IEEE).

[48] Webster's Dictionary (2011), Webster's Dictionary, viewed 1 June 2011, <http://www.merriam-webster.com/>.

[49] Yin, R. K. (2005). Case Study Research: Design and Methods. Newbury Park, CA: Sage.

[50] Zhao, X, Lee, Y, Ng, S and Flynn, B (2009), "The Impact of Product Recall Announcements on Stock Market Reaction: a Study of Chinese Listed Companies", US-China Business Cooperation in the 21st Century: Opportunities and Challenges for Enterpreneurs, 2009.

[51] Zhou, W (2009), "RFID and item-level information visibility", European Journal of Operational Research, Vol 192, pp. 252258. 